Manuel Carrasco Durán - La Jurisprudencia del Tribunal Constitucional ...

\title{
LA JURISPRUDENCIA DEL TRIBUNAL CONSTITUCIONAL ESPAÑOL SOBRE EL DERECHO A LA VIDA
}

\author{
Manuel Carrasco Durán \\ Departamento de Derecho Constitucional \\ Universidad de Sevilla (España)
}

En España, los problemas jurídicos sobre el derecho a la vida no se han planteado en torno a la pena de muerte. La Constitución de 1978 cierra el debate en este tema al establecer en su artículo 15 lo siguiente:

"Todos tienen derecho a la vida y a la integridad física y moral, sin que, en ningún caso, puedan ser sometidos a tortura ni a penas o tratos inhumanos o degradantes. Queda abolida la pena de muerte, salvo lo que puedan disponer las leyes penales militares para tiempos de guerra."

La Constitución, por lo tanto, abole la pena de muerte e impide cualquier intento eventual de reinstaurarla, aunque la abolición puede ser exceptuada en las previsiones de las leyes penales militares para delitos cometidos por militares en tiempos de guerra que deban regirse por dichas leyes específicas. De hecho, el Código Penal Militar mantuvo la pena de muerte para conductas y circunstancias especialmente graves hasta 1995, en que fue también eliminada de aquél por unanimidad de todos los grupos parlamentarios.

El precepto constitucional refleja una amplia corriente social contraria a la pena de muerte, cuyas últimas aplicaciones habían suscitado un fuerte movimiento de presión internacional contra el régimen anterior y un rechazo social que afloró en toda su magnitud tras la eliminación de las trabas al libre debate de la opinión pública que caracterizó la política del régimen del general Franco en materia de libertad de información y opinión. El precepto refleja también el deseo del legislador constituyente de sentar las bases para la más rápida integración posible de España en el marco político y jurídico de los países de Europa Occidental, lo que exigía una claridad en las declaraciones de principios que disipara cualquier duda acerca de la naturaleza democrática del régimen político que iniciaba la constitución y del compromiso por el respeto de los derechos humanos.

Con posterioridad a la promulgación de la Constitución, el propio texto de aquélla ha contribuido a asentar la sensación general de que el tema de la pena de muerte ha sido zanjado. Así, puede decirse que existe un consenso general en la opinión pública sobre la irreversibilidad del mandato constitucional que sólo detecta algunas quiebras en los momentos de conmoción inmediatos a atentados terroristas de gran repercusión. Salvo estos momentos aislados, fruto de la excitación momentánea creada 
por actos criminales particularmente crueles, el tema de la pena de muerte ni siquiera constituye tema de debate público en los medios de comunicación españoles.

Sin embargo, el Tribunal Constitucional sí ha debido pronunciarse sobre el significado del derecho a la vida cuando se han presentado a su enjuiciamiento dos temas especialmente controvertidos: el aborto y la alimentación forzosa de presos por actos de terrorismo en huelga de hambre.

\section{I.- Aborto.}

La sentencia básica sobre el contenido y el significado del derecho a la vida es la $53 / 1985$, de 11 de abril. En ella se decide el recurso previo de inconstitucionalidad ${ }^{25}$ presentado por 54 Diputados contra el Proyecto de Ley Orgánica de Reforma del artículo 417 bis del anterior Código Penal ${ }^{26}$, que, aun manteniendo la tipificación del delito de aborto, despenalizaba el aborto en tres supuestos: necesidad del aborto para evitar un grave peligro para la vida o la salud física o psíquica de la embarazada (aborto terapéutico), embarazos que fueran consecuencia de un hecho constitutivo de violación (aborto ético) y cuando se presumiera que el feto habría de nacer con graves taras físicas o psíquicas (aborto eugenésico).

Esta sentencia suscitó viva polémica en la opinión pública y en los medios de comunicación. La discusión sobre el aborto, además, había sido uno de los principales puntos de fricción en un ambiente político de pugna encendida entre el Partido Socialista (PSOE), entonces en los primeros años de su período de gobierno, y el principal partido de la oposición, que entonces era la conservadora Alianza Popular.

El Tribunal Constitucional hace un razonamiento a partir de círculos concéntricos, mediante el cual se va acercando a la resolución del problema por la progresiva concreción de enunciados generales establecidos con carácter previo.

\section{1.- Significado del derecho a la vida.}

Según el fundamento jurídico 3 de la sentencia, "dicho derecho a la vida, reconocido y garantizado en su doble significación física y moral por el artículo 15 de la Constitución, es la proyección de un valor superior del ordenamiento jurídico constitucional - la vida humana - y constituye el derecho fundamental esencial y troncal en cuanto es el supuesto ontológico $\sin$ el que los restantes derechos no tendrían existencia posible."

\section{2.- La noción de vida.}

El Tribunal Constitucional prosigue afirmando que, pese a reconocer las discrepancias de los especialistas sobre la noción de vida y el momento inicial de ésta, la solución del problema lo obliga a establecer una noción de la vida que le sirva de base

\footnotetext{
${ }^{25}$ El recurso previo de inconstitucionalidad, que podía formularse contra proyectos de Estatutos de Autonomía y Leyes orgánicas e impedía la promulgación del texto en tanto no se resolviera el recurso, fue suprimido por la Ley Orgánica 411985, de 7 de junio. ${ }^{26}$ El Código Penal de 1973 ha sido derogado y sustituido por un nuevo Código Penal, promulgado por Ley Orgánica 10/1995, de 23 de noviembre.
} 
para determinar el alcance del mencionado precepto. En este sentido, realiza tres precisiones: a) que la vida humana es un devenir, un proceso que comienza con la gestación; b) que la gestación genera un tertium existencialmente distinto de la madre, aunque alojado en el seno de ésta; c) "que dentro de los cambios cualitativos en el desarrollo del proceso vital ... tiene particular relevancia el nacimiento... Y previamente al nacimiento tiene especial trascendencia el momento a partir del cual el nasciturus es ya susceptible de vida independiente de la madres, esto es, de adquirir plena individualidad humana" (fundamento jurídico 6).

\section{3.- Consideración jurídica constitucional del nasciturus.}

El Tribunal Constitucional, seguidamente, examina los debates parlamentarios del artículo 15 y el contexto jurídico representado por las normas de derecho civil, la Declaración Universal de Derechos Humanos, el Convenio Europeo de Derechos Humanos y una decisión de la Comisión Europea de Derechos Humanos de 13 de mayo de 1980. Como resultado de su examen, el Tribunal considera que «los argumentos aducidos por los recurrentes no pueden estimarse para fundamentar la tesis que al nasciturus le corresponda también la titularidad del derecho a la vida". Sin embargo, puesto que la vida del nasciturus encarna un valor fundamental - la vida humana garantizado en el artículo 15 de la Constitución, el Tribunal afirma que «la vida del nasciturus ... es un bien jurídico constitucionalmente protegido por el artículo 15 de nuestra norma fundamental.s

La afirmación anterior permite al Tribunal Constitucional establecer unas conclusiones de importancia crucial:

" ... esta protección que la Constitución dispensa al nasciturus implica para el Estado con carácter general dos obligaciones: la de abstenerse de interrumpir o de obstaculizar el proceso natural de gestación, y la de establecer un sistema legal para la defensa de la vida que suponga una protección efectiva de la misma y que, dado el carácter fundamental de la vida, incluya también, como última garantía, las normas penales".

Sin embargo, incluye aún una precisión: "Ello no significa que dicha protección haya de revestir carácter absoluto; pues, como sucede en relación con todos los bienes y derechos constitucionalmente reconocidos, en determinados supuestos puede y aun debe estar sujeta a limitaciones, como veremos posteriormente" (fundamento jurídico 7).

\section{4.- Consideración jurídica constitucional de la posición de la madre.}

La sentencia señala que, junto al valor vida, la Constitución ha elevado también a valor jurídico fundamental la dignidad de la persona (art. 10 de la Constitución), "que se halla íntimamente vinculada con el libre desarrollo de la personalidad (art. 10) y los derechos a la integridad física y moral (art. 15), a la libertad de ideas y creencias (art. 169, al honor, a la intimidad personal y familiar y a la propia imagen (art. 18.1)." Añade el Tribunal que "la dignidad está reconocida a todas las personas con carácter general, pero cuando el intérprete constitucional trata de concretar este principio no puede ignorar el hecho obvio de la especificidad de la condición femenina y la 
concreción de los mencionados derechos en el ámbito de la maternidad, derechos que el Estado debe respetar y a cuya efectividad debe contribuir, dentro de los límites impuestos por la existencia de otros derechos y bienes asimismo reconocidos por la Constitución." (fundamento jurídico 8).

\section{5.- La constitucionalidad de los tres supuestos de aborto que se despenaliza.}

Considera el Tribunal Constitucional que los tres supuestos que el Proyecto de Ley Orgánica pretendía despenalizar suponen graves conflictos de características singulares, en los que entra en colisión la vida del nasciturus, como bien constitucionalmente protegido, con derechos relativos a valores constitucionales de muy relevante significación, como la vida y la dignidad de la mujer. "Ni la vida del nasciturus puede prevalecer incondicionalmente frente a aquéllos, ni los derechos de la mujer pueden tener primacía absoluta sobre la vida del nasciturus". En fin, el legislador "puede también renunciar a la sanción penal de una conducta que objetivamente pudiera representar una carga insoportable, sin perjuicio de que, en su caso, siga subsistiendo el deber de protección del Estado respecto del bien jurídico en otros ámbitos" (fundamento jurídico 9).

De este modo, en cuanto al primer supuesto (grave peligro para la vida y la salud de la embarazada) el Tribunal considera constitucional la despenalización, ya que, de lo contrario, en primer lugar, se protegería más a la vida del no nacido que a la vida del nacido y se penalizaría a la mujer por defender su derecho a la vida, y, en segundo lugar, el grave peligro para la salud de la embarazada afecta seriamente a su derecho a la vida y a la integridad personal, y ello en un grado que, además, plantea la exigencia de un sacrificio importante y duradero de su salud.

En cuanto al segundo supuesto (embarazo como consecuencia de un delito de violación, siempre que el embarazo se interrumpa se practique dentro de las primeras doce semanas), aduce la sentencia que "la gestación ha tenido su origen en la comisión de un acto no sólo contrario a la voluntad de la mujer, sino realizado venciendo su resistencia por la violencia, lesionando en grado máximo su dignidad personal y el libre desarrollo de su personalidad, y vulnerando gravemente el derecho de la mujer a su integridad física y moral, al honor, a la propia imagen y a la intimidad personal. Obligarla a soportar las consecuencias de un acto de tal naturaleza es manifiestamente exigible, y el consentimiento necesario para asumir cualquier compromiso y obligación cobra especial relieve en este caso ante un hecho de tanta trascendencia como el de dar vida a un nuevo ser, vida que afectará profundamente a la suya en todos los sentidos."

Acerca del tercer supuesto (probable existencia de graves taras físicas o psíquicas en el feto) entiende el Tribunal que "el fundamento de este supuesto incluye verdaderos casos límites, se encuentra en la consideración de que el recurso a la sanción penal extrañaría la imposición de una conducta que excede de la que normalmente es exigible a la madre y a la familia. La afirmación anterior tiene en cuenta la situación excepcional en que se encuentran los padres, y especialmente la madre, agravada en muchos casos por la insuficiencia de prestaciones estatales y sociales que contribuyan de modo significativo a paliar en el aspecto asistencias la situación, y a eliminar la inseguridad que inevitablemente ha de angustiar a los padres acerca de la suerte del 
afectado por la grave tara en caso de que les sobreviva". Sobre esta base, la sentencia declara la constitucionalidad, también, de este supuesto (fundamento jurídico 11).

La sentencia, por lo tanto, admite la constitucionalidad de estos supuestos de aborto en razón de su excepcionalidad, aunque ello es así sobre la base de que, en condiciones normales, la vida del nasciturus debe estar protegida por la ley penal. Se establece en la sentencia, por lo tanto, que los supuestos de aborto que se despenalizan son constitucionales dado que las circunstancias excepcionales que los motivan hacen que no pueda exigirse a la mujer la continuación del embarazo, aunque la misma excepcionalidad de los supuestos lleva en sí el límite para la regulación del legislador en supuestos que no planteen peculiaridades reseñables.

\section{6.- Las condiciones médicas para la práctica de la interrupción del embarazo.}

El Tribunal Constitucional, seguidamente, examina las condiciones establecidas en el Proyecto para acceder a la interrupción del embarazo, pues considera que debe controlar que el texto "garantiza suficientemente el resultado de la ponderación de los bienes y derechos en conflicto realizada por el legislador, de forma tal que la desprotección del nasciturus no se produzca fuera de las situaciones previstas ni se desproteján los derechos a la vida y a la integridad física de la mujer".

En este punto, la sentencia señala que el Proyecto no es conforme con la Constitución por las siguientes razones:

a) La requerida intervención de un Médico para practicar el aborto terapéutico no es suficiente, ya que debe ser un Médico de la especialidad correspondiente.

b) En el caso del aborto terapéutico y eugenésico, la comprobación del supuesto de hecho, por su naturaleza, ha de producirse necesariamente con anterioridad a la realización del aborto.

c) El legislador no puede desinteresarse de las condiciones médicas y sanitarias de la interrupción del embarazo, por lo que "debería prever que la comprobación del supuesto de hecho en los casos del aborto terapéutico y eugenésico, así como la realización del aborto.. se lleve a cabo en centros sanitarios públicos o privados, autorizados al efecto, o adoptar cualquier otra solución que estime oportuna dentro del marco constitucional".

Por el contrario, la lentitud de las actuaciones judiciales encaminadas a comprobar la realidad de la violación denunciada hace que sea suficiente para la práctica del aborto en este caso la simple denuncia de la interesada (fundamento jurídico 12).

En consecuencia, el Tribunal decidió, en su fallo, "declarar que el proyecto de Ley Orgánica por el que se introduce el artículo 417 bis del Código Penal es disconforme con la Constitución, no en razón de los supuestos en que declara no punible el aborto, sino por incumplir en su regulación exigencias constitucionales derivadas del artículo 15 de la Constitución, que resulta por ello vulnerado, en los 
términos $y_{\text {con }}$ el alcance que se expresan en el fundamento jurídico 12 de la presente Sentencia ${ }^{27 " .}$.

Las precisiones de la sentencia sobre este tema fueron uno de los puntos de discrepancia que hicieron que aquélla tuviera en su contra el voto particular de seis de los doce Magistrados del Tribunal Constitucional y que saliera adelante sólo gracias al voto de calidad del Presidente del Tribunal. Los Magistrados discrepantes consideraron que el Tribunal se había extralimitado en sus funciones, al entender que la regulación de las condiciones médicas de comprobación de los supuestos de aborto y de práctica de la intervención eran terreno reservado a la libertad de regulación del legislador y que ni siquiera exigían su constancia en la ley penal, pues, según estos Magistrados, podía ser regulado mediante disposiciones reglamentarias específicas.

\section{7.- Otros temas colaterales.}

Los recurrentes consideraban también que el consentimiento en los casos de aborto terapéutico y eugenésico no debería corresponder únicamente a la madre y hacian especial referencia a la participación del padre. En contra, el Tribunal entendió que la solución del Proyecto no era inconstitucional, "dado que la peculiar relación entre la embarazada y el nasciturus hace que la decisión afecte primordialmente a aquélla" (fundamento jurídico 13).

Entendió igualmente el Tribunal que el derecho a la objeción de conciencia del médico cuyas convicciones religiosas, éticas o morales le impidieran participar en la práctica de abortos puede ser ejercido con independencia de que el Proyecto contenga o no regulación alguna sobre la forma de ejercerlo, ya que "la objeción de conciencia forma parte del contenido del derecho fundamental a la libertad ideológica y religiosa reconocido en el artículo 16.1 de la Constitución y, como ha indicado este Tribunal en diversas ocasiones, la Constitución es directamente aplicable, especialmente en materia de derechos fundamentales."

En cuanto a la inexistencia en el Proyecto de una regulación sobre la forma de prestar consentimiento la menor o incapacitada, el Tribunal Constitucional estimó que podía aplicarse la regulación establecida por el derecho positivo (fundamento jurídico $14)^{28}$

\section{8.- Otras sentencias sobre el aborto.}

La sentencia 75/1984, de 27 de junio, fue dictada en un recurso de amparo ${ }^{29}$ contra sendas sentencias de la Audiencia Nacional y del Tribunal Supremo que

\footnotetext{
${ }^{27}$ Las modificaciones impuestas en el Proyecto de Ley Orgánica por el Tribunal Constitucional fueron incorporadas en la Ley Orgánica 9/1985, de 5 de julio, que introdujo en el Código Penal los supuestos de despenalízación del aborto enunciados.

${ }^{28}$ En la actualidad, el Real Decreto 2409/1986, de 21 de noviembre, sobre centros sanitarios acreditados y dictámenes preceptivos para la práctica legal de la interrupción voluntaria del embarazo, desarrolla y concreta las previsiones del código Penal con respecto a estos temas

${ }^{29}$ El recurso de amparo es un proceso especial ante el Tribunal Constitucional cuya finalidad es la protección de los derechos constitucionales de los artículos 14 a 29 y 30.2 de la Constitución. Antes de formular el recurso de amparo se exige al demandante que formule su pretensión a través del procedimiento ante el juez o tribunal ordinario que corresponda, de acuerdo con las prescripciones de las leyes procesales, y que agote todas las instancias establecidas en dichas leyes, de modo que, en
} 
condenaban a los dos recurrentes, a una, como autora de un delito de aborto y, a otro, como cómplice de un delito de aborto, situaciones que, de acuerdo con las sentencias recurridas, habrían de sancionarse según las normas del Código Penal, por aplicación de lo dispuesto en el artículo 339 de la anterior Ley Orgánica del Poder Judicial ${ }^{30}$, al haber acontecido los hechos en Gran Bretaña. El Tribunal Constitucional admite los argumentos de las recurrentes y anula las sentencias recurridas, tomando como base lo siguiente:

a) Las sentencias de la Audiencia Nacional y del Tribunal Supremo apreciaron la existencia de fraude de Ley, pues consideraron que las condenadas (y recurrentes en amparo) utilizaron el artículo 339 de la anterior Ley Orgánica del Poder Judicial (entonces vigente), que hacía punibles los delitos cometidos en el extranjero por españoles contra otros españoles, para eludir los artículos del Código Penal que castigan el aborto.

Sin embargo, el Tribunal Constitucional entiende que no existe fraude de Ley, ya que no existe norma de cobertura. En particular, frente a la norma del artículo 339 de la Ley Orgánica del Poder Judicial, se erigía el artículo 333 de la misma Ley, que, en concordancia con lo que dispone el artículo $8^{2} .1$ del Código Civil, establecía la territorialidad de las leyes penales (fundamentos jurídicos 5 y 6 ). En términos generales, no cabe hacer uso de la figura del fraude de Ley en la aplicación de la Ley penal, "pues la territorialidad de ésta (art. 8․1 del Código Civil) y la inexistencia en ella de normas disponibles a cuyo amparo puedan producirse consecuencias jurídicas favorables hacen resueltamente imposible extender a este sector del ordenamiento la figura del fraude de Ley" (fundamento jurídico 5).

b) El artículo 339 no puede utilizarse considerando que el feto deba ser considerado como español porque el razonamiento que lleva a atribuir nacionalidad española al feto tiene una evidente naturaleza analógica, prohibida en derecho penal (fundamento jurídico 6).

c) La interpretación teleológica del artículo 339 que proponían las sentencias recurridas era imposible porque el telos no se extraía o se deducía de la norma que se interpretaba, sino de las normas del Código Penal que castigan el aborto y, sobre todo, del artículo 15 de la Constitución, que protege el derecho a la vida. En particular, con respecto al artículo 15, "no hay inconveniente en reconocer ... que, según este precepto, la vida humana en formación es un bien que constitucionalmente merece protección, pero de esta premisa no se sigue, en modo alguno, que los particulares tengan al respecto otros deberes sancionados que el de abstenerse de aquellas conductas que la Ley penal castiga" (fundamento jurídico 6).

realidad, la protección de primera mano de los derechos constitucionales en el derecho constitucional español está encomendada a los órganos judiciales ordinarios $y$, desde este punto de vista, el sistema de protección de derechos constitucionales no es tan diferente del chileno como pudiera parecer a primera vista. Dada la estructura del sistema en España, el recurso de amparo se formulará, en su caso típico, contra las resoluciones judiciales que resuelven el asunto en la vía procesal previa al amparo.

Puede decirse que, muy a grosso modo, el recurso de amparo ante el Tribunal Constitucional equivale a la última instancia del recurso de protección de derechos constitucionales ante la Corte Suprema chilena. No debe confundirse el recurso de amparo español con el recurso chileno del mismo nombre, que en España tiene su equivalente en el proceso de habeas corpus.

${ }^{30}$ La Ley Orgánica del Poder Judicial de 1870 fue derogada y sustituida por la actual Ley Orgánica 611985, de 1 de julio, del Poder Judicial. 
En conclusión, la sentencia anula las sentencias del Tribunal Supremo y de la Audiencia Nacional, por vulnerar el derecho del artículo 25.1 de la Constitución a no ser condenados por acciones u omisiones que en el momento de someterse no constituyan delito o falta según la legislación vigente, y reconoce el derecho de los recurrentes a no ser condenados en España por el aborto cometido en el extranjero.

Otra sentencia sobre el tema es la 70/1985, de 31 de mayo, en la que los recurrentes impugnaban la sentencia del Tribunal Supremo que las condenaba a consecuencia de sendos delitos de aborto en grado de tentativa, pese a no haberse demostrado el estado de embarazo de las recurrentes, por aplicación del segundo párrafo del artículo 52 del anterior Código Penal, que equiparaba a la tentativa los casos de imposibilidad de ejecución o de producción del delito. En concreto, considera que la punición del delito imposible ni produce la inversión de la carga de la prueba ni da lugar a una supuesta presunción de culpabilidad, ya que "quien formule la acusación tendrá que aportar ante el Tribunal prueba suficiente de que el acusado dio comienzo a la ejecución de actos externos inequívocamente enderezados a la producción de un aborto con el propósito deliberado - o al menos con el dolo eventual - de interrumpir un embarazo que creía o suponía cierto, y de no llevarse a cabo tal prueba, ninguna imputación de culpabilidad podría actuar contra el acusado" (fundamento jurídico I). Además, carece de lógica la alegación de una pretendida vulneración del derecho a la igualdad del artículo 14 de la Constitución por la absolución por parte del Tribunal de otros acusados en razón de la retirada de acusación contra algunos de ellos, prescripción del delito, tentativa desistida y no realización de los hechos imputados, todos ellos previos los adecuados razonamientos amparadores de tales pronunciamientos (fundamento jurídico 4). Finalmente, la apreciación de la eximente de extrema necesidad es una cuestión de mera interpretación y aplicación de la legalidad ordinaria en la que no puede entrar el Tribunal Constitủci(@ablamento jurídico 5). Por todo ello, la sentencia desestima la pretensión de los recurrentes.

\section{II.- Alimentación forzosa de reclusos en huelga de hambre pertenecientes a una banda terrorista:}

Este asunto se decidió en la sentencia 120/1990, de 27 de junio, que resuelve un recurso de amparo contra un auto de la Audiencia Provincial de Madrid que declaró el derecho - deber de la Administración penitenciaria de suministrar asistencia médica, cuando su vida corriere peligro conforme a criterios de ciencia médica, a determinados reclusos, pertenecientes a la banda terrorista GRAPO, que se habían declarado en huelga de hambre al objeto de forzar al Gobierno al agrupamiento en un centro penitenciario de los presos de dicha banda. La doctrina de esta sentencia fue reiterada en la posterior sentencia $137 / 1990$, de 19 de julio, que resolvió otro recurso de amparo sobre el mismo tema.

\footnotetext{
${ }^{31}$ El Tribunal Constitucional ha declarado repetidamente que su competencia se limita a las cuestiones que deban resolverse utilizando como parámetro jurídico los preceptos de la Constitución que recogen los derechos constitucionales. Por lo tanto, quedan fuera de su jurisdicción cuestiones tales como la aplicación de la legalidad ordinaria o la apreciación de la prueba llevada a cabo por los jueces y tribunales ordinarios, salvo que el resultado de aquella aplicación o de tal apreciación conduzca a una interpretación inconstitucional de la ley o a resultados arbitrarios desproporcionados o manifiestamente erróneos.
} 


\section{1.- Concepto de derecho a la vida.}

"El derecho fundamental a la vida, en cuanto derecho subjetivo, da a sus titulares la posibilidad de recabar el amparo judicial y, en último término, el de este Tribunal frente a toda actuación de los poderes públicos que amenace su vida o su integridad. De otra parte y como fundamento objetivo del ordenamiento impone a esos mismos poderes públicos y en especial al legislador, el deber de adoptar las medidas necesarias para proteger esos bienes, vida e integridad física, frente a los ataques de terceros, sin contar para ello con la voluntad de sus titulares e incluso cuando ni siquiera quepa hablar, en rigor, de titulares de ese derecho" (fundamento jurídico 7). En este punto, la sentencia reitera doctrina sentada en la sentencia 53/1985.

\section{2.- Tratamiento jurídico constitucional de la muerte.}

Del concepto anterior deriva la sentencia que "tiene, por consiguiente, el derecho a la vida un contenido de protección positiva que impide configurarlo como un derecho de libertad que incluya el derecho a la propia muerte. Ello no impide, sin embargo, reconocer que, siendo la vida un bien de la persona que se integra en el círculo de su libertad, pueda aquélla tácticamente disponer sobre su propia muerte, pero esa disposición constituye una manifestación del agere licere, en cuanto que la privación de la vida propia o la aceptación de la propia muerte es un acto que la ley no prohibe y no, en ningún modo, un derecho subjetivo que implique la posibilidad de movilizar el apoyo del poder público para vencer la resistencia que se oponga a la voluntad de morir, ni mucho menos, un derecho subjetivo de carácter fundamental en el que esa posibilidad se extienda incluso frente a la resistencia del legislador, que no puede reducir el contenido esencia del derecho.

En virtud de ello, no es posible admitir que la Constitución garantice en su artículo 15 el derecho a la propia muerte $y$, por consiguiente, carece de apoyo constitucional la pretensión de que la asistencia médica coactiva es contraria a ese derecho constitucionalmente inexistente" (fundamento jurídico 7).

\section{3.- Relevancia de la motivación que lleva a la huelga de hambre.}

"Una vez establecido que la decisión de arrostrar la propia muerte no es un derecho, sino simplemente manifestación de libertad genérica, es oportuno señalar la relevancia jurídica que tiene la finalidad que persigue el acto de libertad de oponerse a la asistencia médica, puesto que no es lo mismo usar de la libertad para conseguir fines lícitos que hacerlo con objetivos no amparados por la ley, y, en tal sentido, una cosa es la decisión de quien asume el riesgo de morir en un acto de voluntad que sólo a él afecta, en cuyo caso podría sostenerse la ilicitud de la asistencia médica obligatoria o de cualquier otro impedimento a la realización de esa voluntad, y cosa bien distinta es la decisión de quienes, hallándose en el seno de una relación especial penitenciaria, arriesgan su vida con el fin de conseguir que la Administración deje de ejercer o ejerza de distinta forma potestades que le confiere el ordenamiento jurídico; pues, en este caso, la negativa a recibir asistencia médica sitúa al Estado, en forma arbitraria, ante el injusto de modificar una decisión, que el legítima mientras no sea judicialmente 
anulada, o contemplar pasivamente la muerte de personas que están bajo su custodia y cuya vida está legalmente obligado a preservar y proteger" (fundamento jurídico 7).

Anteriormente había señalado ya la sentencia que, si bien los derechos fundamentales admiten en determinadas circunstancias limitaciones, estas limitaciones adquieren particular intensidad en el desarrollo de relaciones de especial sujeción de los particulares a la Administración, entre las que se encuentra la reclusión en un centro penitenciario, "y así se desprende directamente de la propia Constitución, cuyo artículo 25.2 , en atención al estado de reclusión en que se encuentran las personas que cumplen penas de privación de libertad, admite que los derechos constitucionales de estas personas puedan ser objeto de limitaciones que no son de aplicación a los ciudadanos comunes $y$, entre ellas, las que se establezcan en la ley penitenciaria, que regula el estatuto especial de los recluidos en centros penitenciarios". Y aunque esta relación de especial sujeción "debe ser siempre en un sentido reductivo compatible con el valor preferente que corresponde a los derechos fundamentales", de modo que no dé pie a más restricciones que las estrictamente indispensables, permite, "en determinadas situaciones, imponer limitaciones a los derechos fundamentales de internos que se colocan en peligro de muerte a consecuencia de una huelga de hambre reivindicativa, que podrían resultar contrarias a esos derechos si se tratara de ciudadanos libres o incluso internos que se encuentren en situaciones distintas" (fundamento jurídico 6).

Termina la sentencia señalando que "en síntesis de todo lo expuesto, debemos finalizar con la conclusión de que la asistencia médica obligatoria autorizada por la resolución judicial objeto del recurso de amparo no vulnera ninguno de los derechos fundamentales invocados por los demandantes, ni en sí misma, ni en la forma y alcance con que ha sido autorizada, constituyendo tan sólo una limitación del derecho a la integridad física y moral garantizada por el artículo 15 de la Constitución.. y unida ineludiblemente a ella una restricción a la libertad física, que vienen justificadas en la necesidad de preservar el bien de la vida humana, constitucionalmente protegido, y que se realiza mediante un ponderado juicio de proporcionalidad, en cuanto entraña el mínimo sacrificio del derecho que exige la situación en que se hallan aquéllos respecto de los cuales se autoriza" (fundamento jurídico 12).

\section{4.- Comentario de la sentencia.}

La sentencia decide sobre un tema controvertido ${ }^{32}$, de innegables connotaciones éticas, en el que, en la práctica, se manifiesta el conflicto entre, por una parte, la libertad de los reclusos para disponer sobre su vida y para llevar a cabo su protesta contra la política penitenciaria del Gobierno por vías pacíficas, y, por otra parte, el interés del Estado en mantener las condiciones de vida y seguridad de las prisiones, en evitar la publicidad que la acción de los internos daría a la banda a la que pertenecían y las corrientes de simpatía (incluso en la escena internacional) que produce este tipo de actitudes "numantinas" en ciertos sectores de la opinión pública, y, finalmente, en mantener su política penitenciaria frente a las expresiones de disconformidad de los propios reclusos a quienes va destinada. Prueba de lo controvertido del asunto son los dos votos particulares discrepantes de la sentencia que formularon otros tantos Magistrados.

${ }^{2}$ De hecho, la sentencia tuvo en contra el voto particular de dos Magistrados. 


\section{La fundamentación de la sentencia gira en torno a tres puntos:}

a) Primero, el derecho a la vida no incluye el derecho a la propia muerte. La persona puede disponer sobre su vida causándose la muerte, pero no puede exigir la colaboración del Estado para llevar a su fin el medio escogido con vistas a procurarse la muerte.

b) Segundo, la Administración tiene un derecho - deber ${ }^{33}$ de mantener con vida a los reclusos en centros penitenciarios. Esta función de la Administración, por lo tanto, no sólo supone el deber de velar por la vida de aquéllos, sino que también entraña, al mismo tiempo, un derecho a mantener la vida de los mismos, en el cual no es difícil descubrir la protección del interés del Estado en evitar circunstancias problemáticas que pudieran alterar la frágil normalidad de las condiciones de vida en los centros penitenciarios y la seguridad de éstos, así como en afirmar su política penitenciaria frente a instrumentos de protesta que, por sus características, pudieran suponer una presión extraordinaria contra los órganos responsables de dicha política.

c) Finalmente, la naturaleza de la relación entre los reclusos y la Administración penitenciaria, caracterizada como relación de sujeción especial en razón del peculiar vínculo que une a la Administración penitenciaria y a quienes se encuentran recluidos en los centros dependientes de dicha Administración ${ }^{34}$.

Por lo tanto, la sentencia reduce la cuestión del pretendido derecho a la propia muerte a una mera disponibilidad sobre un bien jurídico propio (la vida) en cuanto dicha disponibilidad dependa únicamente de la propia voluntad. La manifestación de libertad genérica que constituye la decisión de causarse la muerte puede ser obstaculizada lícitamente en razón de fines propios de la política penitenciaria del Estado.

Sin embargo, la sentencia "se despista", si vale esta expresión, cuando señala "la relevancia jurídica que tiene la finalidad que persigue el acto de libertad de oponerse a la asistencia médica, puesto que no es lo mismo usar de la libertad para conseguir fines lícitos que hacerlo con objetivos no amparados por la ley". La protesta contra una medida del Gobierno nunca puede considerarse como supuesto de uso ilícito de la libertad, más aun cuando la Constitución reconoce en su artículo 16 la "libertad ideológica". Por ello, la sentencia debió argumentar la restricción en la facultad de los reclusos de disponer sobre su propia muerte que suponían las medidas de alimentación forzosa dictadas por la Administración penitenciaria tomando como base el daño que el desarrollo de la huelga de hambre hasta extremos críticos podía causar en el interés del Estado en procurar la normalidad en la vida de los centros penitenciarios, el aislamiento social de opciones que propugnen la violencia como instrumento político y la eficacia de

\footnotetext{
${ }^{33}$ Estas situaciones de derecho - deber son conocidas en distintos sectores del ordenamiento jurídico. Así, la patria potestad, por ejemplo, se configura hoy como derecho de los padres a la custodia, educación, etc. de sus hijos, pero también como deber de aquéllos de proporcionarles a sus hijos alimentación, vestido, educación y de cumplir cuantos otros deberes establece el ordenamiento jurídico en razón de la protección de los hijos.

${ }^{34}$ El concepto de relaciones de sujeción especial es muy difuso. pero. genéricamente, pueden entenderse como tales las que surgen por causa de la situación de especial vinculación que une a determinados ciudadanos con la Administración, en razón del interés público que la Administración tiene en el adecuado desarrollo de una determinada actividad o función a su cargo (es una relación de sujeción especial también, por ejemplo, la que vincula a los funcionarios con la Administración en la que prestan sus servicios).
} 
su política penitenciaria en relación con los integrantes de bandas terroristas, sin incidir tanto en la pretendida ilicitud de los motivos de la protesta.

La sentencia 11/1991, de 17 de enero, señala que "establecer el momento y la forma en que haya de procederse de manera coactiva para evitar riesgos intolerables para la vida del interno, no es algo que corresponda hacer a este Tribunal, dado que ello supondría una clara injerencia en la competencia propia de la Administración Penitenciaria $y$, en su caso, de los órganos judiciales establecidos al efecto" (fundamento jurídico 4). Por lo tanto, se deja a la apreciación de la Administración Penitenciaria el momento en que deba comenzar a suministrarse la alimentación forzosa.

\section{III.- La inexistencia de un derecho de reducción de las penas de quienes están condenados a penas privativas de libertad, en caso de que a un condenado a pena de muerte se le conmute ésta por una pena privativa de libertad.}

El auto 35 32/1981, de 25 de marzo resuelve un caso en que el recurrente, que había sido condenado a muerte por sentencia del Tribunal Supremo de 10 de diciembre de 1974 y cuya pena capital le había sido conmutada por la de reclusión mayor en abril de 1975, pidió que se le aplicara el indulto concedido por Real Decreto 2940/1975, de 25 de abril, que preveía, junto a esta medida de gracia, la conmutación por la de reclusión mayor de todas las penas de muerte pendientes de ejecución en esa fecha, sí bien excluía toda reducción de condena en favor de quienes sufrieran penas de privación de libertad sustitutorias de una condena a la pena capital.

El Tribunal Constitucional entiende que la conmutación de una pena de muerte por otra privativa de libertad no supone ninguna consecuencia en relación con una pretendida rebaja de las pena privativas de libertad que sufran los condenados a los cuales les hubiera sido conmutada la pena de muerte con anterioridad, observación que puede extenderse, sin problemas, a quienes hayan sido condenados, desde un principio, a penas privativas de libertad. Según la resolución, "la consagración constitucional del derecho a la vida y la correlativa abolición de la pena de muerte erradican esta pena de nuestro ordenamiento e impiden, ciertamente, la ejecución de las que se encontraran pendientes, pero no amplían el alcance de las medidas generales de gracia anteriormente concedidas" (fundamento jurídico 4).

\footnotetext{
${ }^{35}$ Los autos son resoluciones de inadmisión de los recursos de amparo (en este caso, la inadmisión se produjo por falta manifiesta de contenido que justifique una Decisión del Tribunal Constitucional en cuanto al fondo del asunto.
} 